\title{
Revisiting Covered Interest Parity in the European Union: the DCCA Approach
}

\section{Paulo Ferreira \& Andreia Dionisio}

To cite this article: Paulo Ferreira \& Andreia Dionisio (2015): Revisiting Covered Interest Parity in the European Union: the DCCA Approach, International Economic Journal, DOI: 10.1080/10168737.2015.1081260

To link to this article: http://dx.doi.org/10.1080/10168737.2015.1081260

曲 Published online: 22 Sep 2015.

Submit your article to this journal $\pi$

Џ Article views: 8

Q View related articles \ulcorner

$\bigotimes_{\text {Crossmark }}$ View Crossmark data־ 


\title{
Revisiting Covered Interest Parity in the European Union: the DCCA Approach
}

\author{
PAULO FERREIRA*,**,† \& ANDREIA DIONISIO*
}

\author{
*CEFAGE-UE, IIFA, Universidade de Évora, Évora, Portugal; ** Instituto Superior de \\ Linguas e Administração de Leiria, Portugal; ${ }^{\dagger}$ Departamento de Ciência e Tecnologia \\ Animal, Escola Superior Agrária de Elvas, Instituto Politécnico de Portalegre, Portugal
}

(Received 27 November 2014; in final form 3 July 2015)

\begin{abstract}
This paper analyzes the evidence of financial integration, with covered interest parity (CIP), for a group of countries that have already adopted the euro and another group of countries that kept their currencies. We use detrended crosscorrelation analysis, which allows analyzing the behavior of time series even when they are not stationary. The main results indicate that countries that adopted the euro do not show much evidence in favor of CIP, before joining the Eurozone, which could imply they will not benefit from all common currency advantages. In the group of countries that did not adopt the euro, Denmark, Sweden, the UK and the Czech Republic are the ones presenting better conditions for financial integration with the euro, while Bulgaria has also some evidence of this. Some possible explanations of CIP deviations are agents not considering all countries' assets as similar and also the underdevelopment of markets and liquidity problems (more pronounced due to periods of turmoil).
\end{abstract}

KEY WORDS: Financial integration, common currency, long-range correlation, detrended cross-correlation analysis, euro

JEL CLASSIFICATIONS: G15, E43, E44, F36

Correspondence Address: Paulo Ferreira, CEFAGE-UE, IIFA, Universidade de Évora, Largo dos Colegiais 2, 7000 Évora, Portugal. Email: pjsf@uevora.pt 


\section{Paulo Ferreira \& Andreia Dionísio}

\section{Financial Integration: A Brief Literature Review}

The decision to adopt a common currency brought many benefits to the countries involved. Among these benefits, we can name better allocation of savings, which will lead to better investment returns, allowing countries to reach better economic performance, with increasing levels of consumption. Financial integration, which means that financial markets are closely linked together, also leads to reduced borrowing costs (due to more competition), lower intermediation costs (for the same reason) and the harmonization of product prices and financial services. In fact, with financial integration between countries, we can expect higher market efficiency.

However, financial integration is also an institutional challenge. First, a rapid integration of financial markets (noted by the increase in the volume of capital flow between countries) could increase currencies' exposure to risk, facilitating the emergence of crisis on a global scale. In addition, and probably more importantly, when countries decide to adopt a common currency, they lose their monetary authority which could be an important instrument to combat possible asymmetric shocks in their economy. In the context of integrated economics, an asymmetric shock is an event that occurs in a given country and not in all integrated countries. Therefore, it is more difficult to take measures to face that shock. So adopting the euro when financial integration is not complete could result in greater disparities between countries. ${ }^{1}$

We base our study on covered interest parity (CIP) which is considered as a pure criterion of capital mobility (see, for example, Frankel, 1992). With instruments that cover exchange risks, investors carry out arbitrage operations and eliminate differentials between the returns on similar assets (similar in maturity, political and sovereign risks, among others) except in currency denomination. With capital mobility between countries, arbitrage assures that differentials, which represent riskless profits, are eliminated. Frankel (1993) shows that we only need the abolition of capital controls to have reduced profit opportunities.

The Eurozone now has 18 members. In the first phase, 12 countries adopted the euro: Austria, Belgium, Finland, France, Germany, Greece, Luxembourg, Ireland, Italy, the Netherlands, Portugal and Spain. Several studies have been made of these countries, regarding financial integration, before their decision to adopt the common currency. In addition, the same methodology we apply in this paper was also applied to those countries, showing that Central European countries could foresee better financial integration, while Southern European countries showed some non-verification of CIP (see, for example, Ferreira, Dionision, \& Pires, 2010, or Ferreira, 2011).

In recent years, other countries have adopted the euro (Slovenia in 2007, Cyprus and Malta in 2008, Slovakia in 2009, Estonia in 2011 and Latvia in 2014) and Lithuania entered the currency union at the beginning of 2015.

\footnotetext{
${ }^{1}$ For more information about the benefits and risks of financial integration see, for example, Lemmen (1996).
} 
Some of these countries are analyzed in this paper, namely Slovakia, Estonia and Latvia. ${ }^{2}$ Besides these countries, we also study verification of CIP in other non-euro countries, to evaluate whether they are in a position to support a future decision to adopt the euro. In fact, due to the advantages and disadvantages of adopting a common currency, evidence of financial integration is an important way to study whether a country will benefit from all the advantages of financial integration.

The main objective of this study is to analyze verification of CIP in these countries. For countries that have already adopted the euro, this was important because they should verify this condition to explore all the potentialities of the common currency. For countries that may adopt the euro in the future, it is also important to analyze if that decision will be correct or not. We made this analysis using a relatively recent methodology: detrended crosscorrelation analysis (DCCA). As far as we know, this methodology has never been used to study financial integration in these countries.

The remainder of the paper is organized as follows: Section 2 presents CIP conditions and presents some different ways to analyze this. Section 3 presents data and the methodology used in this study (DCCA and its correlation coefficient). Section 4 reports on the empirical analysis and its results and Section 5 concludes.

\section{Covered interested parity}

Considering forward contracts as the instruments to cover risks, we can formalize CIP in short maturities (less than one year) as follows:

$$
\frac{F_{t+1}}{S_{t}}=\frac{1+i_{t}^{*}}{1+i_{t}}
$$

where $i$ is the nominal interest rate, $S$ the spot exchange rate, ${ }^{3} F$ the forward exchange rate and the symbol * is used for foreign variables (since we compare CIP with the euro, it refers to the Euribor rate). Taking the logarithm of the previous equation we get: ${ }^{4}$

$$
f_{t+1}-s_{t}=i_{t}^{*}-i_{t}
$$

Rearranging the previous equation, and isolating the national rate, we have

$$
i_{t}=i_{t}^{*}-\left(f_{t+1}-s_{t}\right)
$$

Defining $i c_{t}^{*}=i_{t}^{*}-\left(f_{t+1}-s_{t}\right)$ as the covered foreign rate and including an error term, we have the equation $i_{t}=i c_{t}^{*}+\varepsilon_{t}$, where $\varepsilon$ is a Gaussian error.

\footnotetext{
${ }^{2}$ Our sample does not include all those countries due to lack of data availability.

${ }^{3}$ Units of foreign currency per unit of domestic currency

${ }^{4}$ We assume that $\ln (1+z)=z$, an assumption normally used when $z$ is a small value in relation to 1 .
} 


\section{Paulo Ferreira \& Andreia Dionísio}

Table 1. Beginning of samples and number of observations used in the study

\begin{tabular}{llc}
\hline Country & Date of beginning & Number observations \\
\hline Estonia & 29 March 2004 & 1765 \\
Latvia & 29 March 2004 & 2547 \\
Slovakia & 11 February 2002 & 1798 \\
Bulgaria $^{a}$ & 29 March 2004 & 2671 \\
Czech Republic $_{\text {Denmark }}$ & 1 January 1999 & 4037 \\
Hungaryb & 1 January 1999 & 4037 \\
Lithuania & 1 January 1999 & 4037 \\
Poland & 29 March 2004 & 2671 \\
Romania & 11 February 2002 & 3226 \\
Swedenc & 29 March 2004 & 2671 \\
UK & 1 January 1999 & 4037 \\
\hline
\end{tabular}

${ }^{\text {a }}$ For 6 and 12-month maturity, sample only begins on 5 October 2007, with $n=1752$.

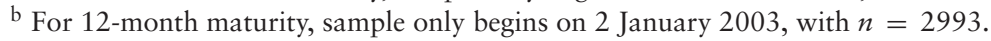

${ }^{\mathrm{c}}$ For 12-month maturity, sample ends on 1 March 2013, with $n=3696$.

Table 2. Long-range average correlation coefficient for different maturities and countries

\begin{tabular}{lrrrr}
\hline Country & 1 month & 3 months & 6 months & 12 months \\
\hline Estonia & 0.1581 & -0.1058 & -0.3475 & -0.1495 \\
Latvia & -0.2579 & -0.5281 & -0.2747 & -0.2669 \\
Slovakia & 0.1262 & -0.1836 & -0.4002 & -0.5488 \\
Lithuania & 0.2298 & -0.2701 & -0.4776 & -0.5524 \\
Denmark & 0.7438 & 0.6957 & 0.6816 & 0.6713 \\
Sweden & 0.1944 & 0.1245 & 0.4982 & 0.0766 \\
UK & 0.6854 & 0.6197 & 0.4768 & 0.0443 \\
Bulgaria & 0.4155 & 0.2018 & 0.0247 & -0.2537 \\
Czech Republic & 0.4263 & 0.3275 & 0.1698 & -0.0236 \\
Hungary & 0.0208 & 0.0353 & -0.1285 & -0.5760 \\
Poland & 0.0181 & 0.0952 & 0.0345 & -0.1677 \\
Romania & -0.0405 & -0.1882 & -0.5386 & -0.6086 \\
\hline
\end{tabular}

In order to test CIP empirically, we need to estimate the following equation:

$$
i_{t}=\alpha+\beta i c_{t}^{*}+\varepsilon_{t}
$$

CIP holds when $\alpha=0$ and $\beta=1$; thus, testing CIP is equivalent to testing these two conditions. Transaction costs, obstacles preventing capital mobility such as government restrictions to capital circulation and political risk ${ }^{5}$ are detected in the constant term, with this showing a non-zero value. On the other hand, the constant detects differentials due to differences in the fiscal treatment of returns, financial restrictions imposed by governments or data imperfections.

${ }^{5}$ See Aliber (1973). Political risk is the probability of future government intervention in financial markets. It tells us that if an investor anticipates the government's intention to impose obstacles to capital mobility, he will demand an extra premium for his investment. 


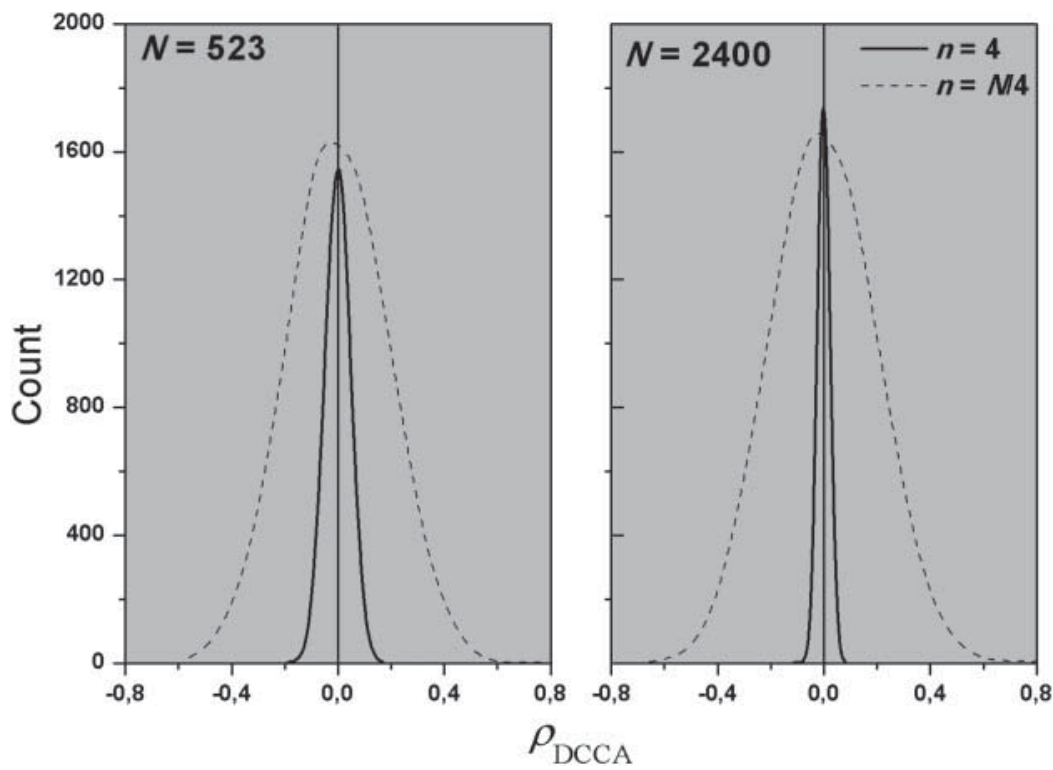

Figure 1. Behavior at $95 \%$ confidence levels, for different numbers of observations.
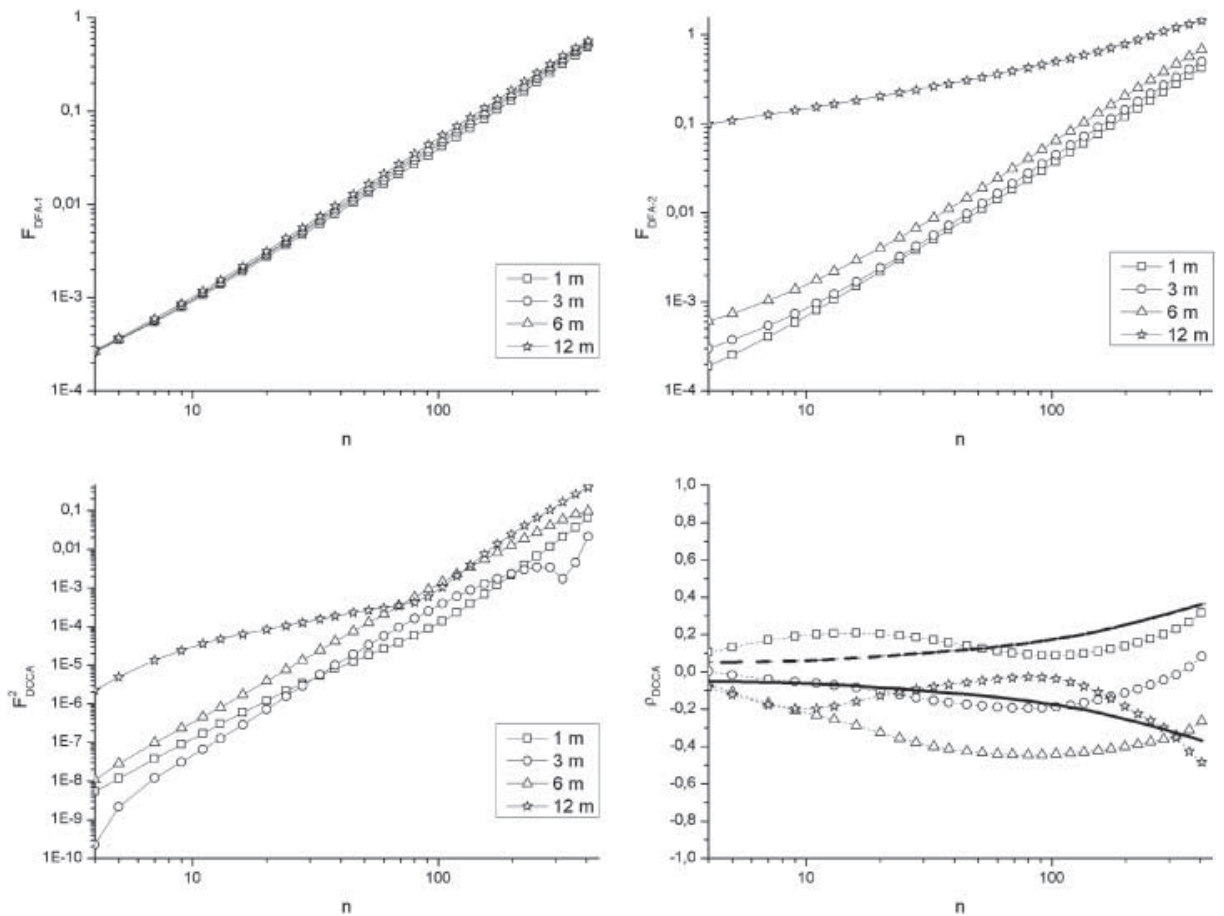

Figure 2. DCCA correlation coefficient for Estonia. 


\section{Paulo Ferreira \& Andreia Dionísio}

CIP conditions could be studied in different ways. One of the most common is to analyze CIP differentials, analyzing the stationarity of $\varepsilon_{t}=i_{t}-i c_{t}^{*}$. Almost all studies use information from Central European countries and the results generally point to confirmation of CIP. For example, the work by Ferreira (2011), Holmes (2003) or Holmes and Pentecost (1996), among others, finds differentials that are eliminated over time, showing evidence in favor of financial EU integration. Few cases, with these countries, show evidence against CIP. One is the study by Holmes and Wu (1997), who find significant covered interest differentials. Exchange rate turbulence and German unification in 1990, an asymmetric shock, are the reasons advanced for these results. However, when more peripheral countries are included in samples, results show that financial integration is not complete. For example, the study by Ferreira (2011) shows that countries such as Greece, Ireland, Italy, Portugal or Spain present some violations of CIP. Concerning Eurozone countries, they do not show great evidence of CIP, which is coherent with previous studies. It means that countries where CIP is violated could face some problems in the case of asymmetric shocks. For other countries, Denmark, Sweden, the UK, Bulgaria and the Czech Republic show some evidence of these financial integration criteria.

Another approach could be the direct analysis of equation (4), but as both series used in the equation are commonly non-stationary, methodologies could not use Ordinary Least Squares. However, studying co-integration could give information about confirmation or not of CIP in its weak form.
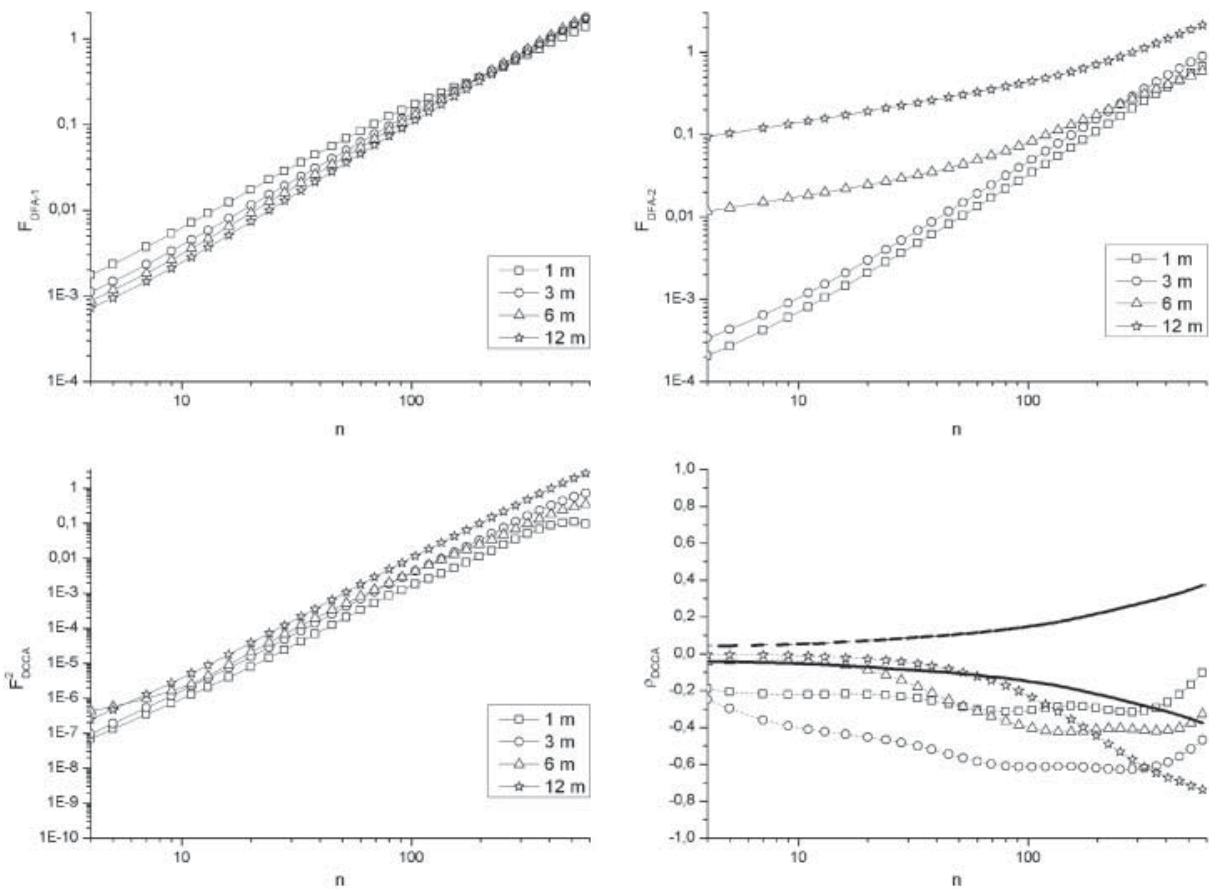

Figure 3. DCCA correlation coefficient for Latvia. 
Some studies also use this methodology and the results are similar to those found when analyzing CIP differentials (see, for example, Ferreira, 2011).

Besides this, the development of econometric methodologies allows researchers to use alternative methodologies. General Maximum Entropy is one of these methodologies and allows, for co-integrated series, direct analysis of equation (4). Ferreira et al. (2010) used this methodology and found, once again, that Central European countries show more evidence of CIP than Southern European ones.

In this paper we propose analysis of CIP conditions using methodologies that are originally used in physical statistics.

\section{Data and Methodology}

As already mentioned, we propose to analyze financial integration in several European Union countries, divided in two different groups. We exclude the first group of countries that adopted the euro because they have already been studied using this methodology (Ferreira, Dionísio, \& Zebende, 2014). One of the groups is composed of countries that adopted the euro more recently: Estonia, Latvia and Slovakia. Data were available for these countries and, in this case, the dataset ends on the last day of their former currencies (respectively, 31 December 2010, 2013 and 2008).
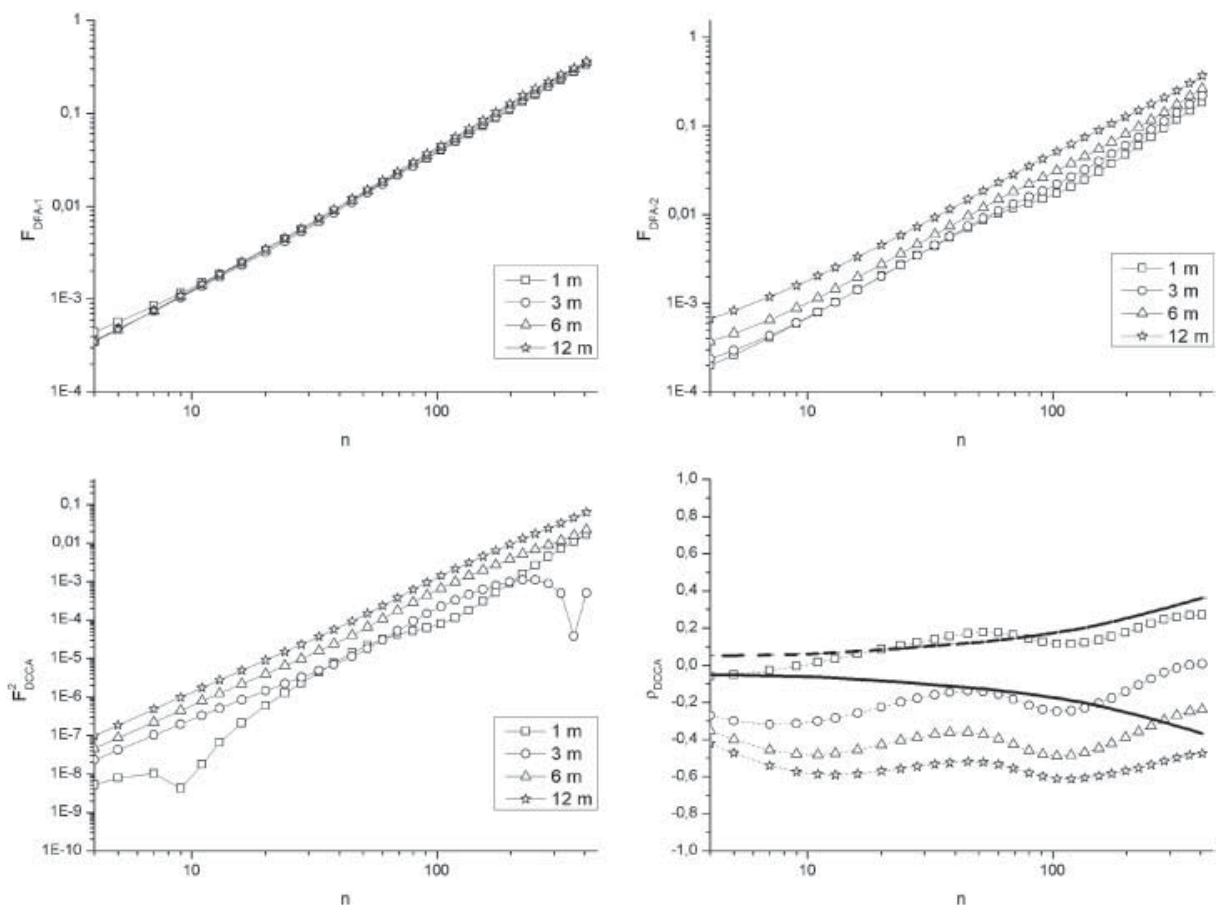

Figure 4. DCCA correlation coefficient for Slovakia. 
For all other countries, the dataset ends on 23 June 2014. Lithuania joined the euro at the beginning of 2015, so this is a very important analysis regarding its decision. The remaining countries (Bulgaria, the Czech Republic, Denmark, Hungary, Poland, Romania, Sweden and the UK are not in the eurogroup) are also analyzed.

We test CIP using assets with maturity up to 12 months $(1,3,6$ and 12 months), made with onshore assets: interbank interest rates, in the currency of each country. To study financial integration we have to use spot and forward exchange rates for each country in relation to the euro. We use daily data from DataStream. Choice of this database is due to relative homogeneity within the data. Samples were recovered according to data availability and information about the samples is given in Table 1 .

When we want to compare behavior between series using financial time series, one problem is the possibility of non-stationarity, which prevents us from using some econometric techniques. Even if series are co-integrated, Ordinary Least Squares results cannot be fully interpreted because the hypothesis analyzes the correlation between series (even though generating estimates that are super-consistent).

In this context, Podobnik and Stanley (2008) developed DCCA, a method that can calculate the cross-correlation between two non-stationary series. It is a generalization of Detrended Fluctuation Analysis (DFA), a technique used to analyze temporal dependence in time series with the advantage of
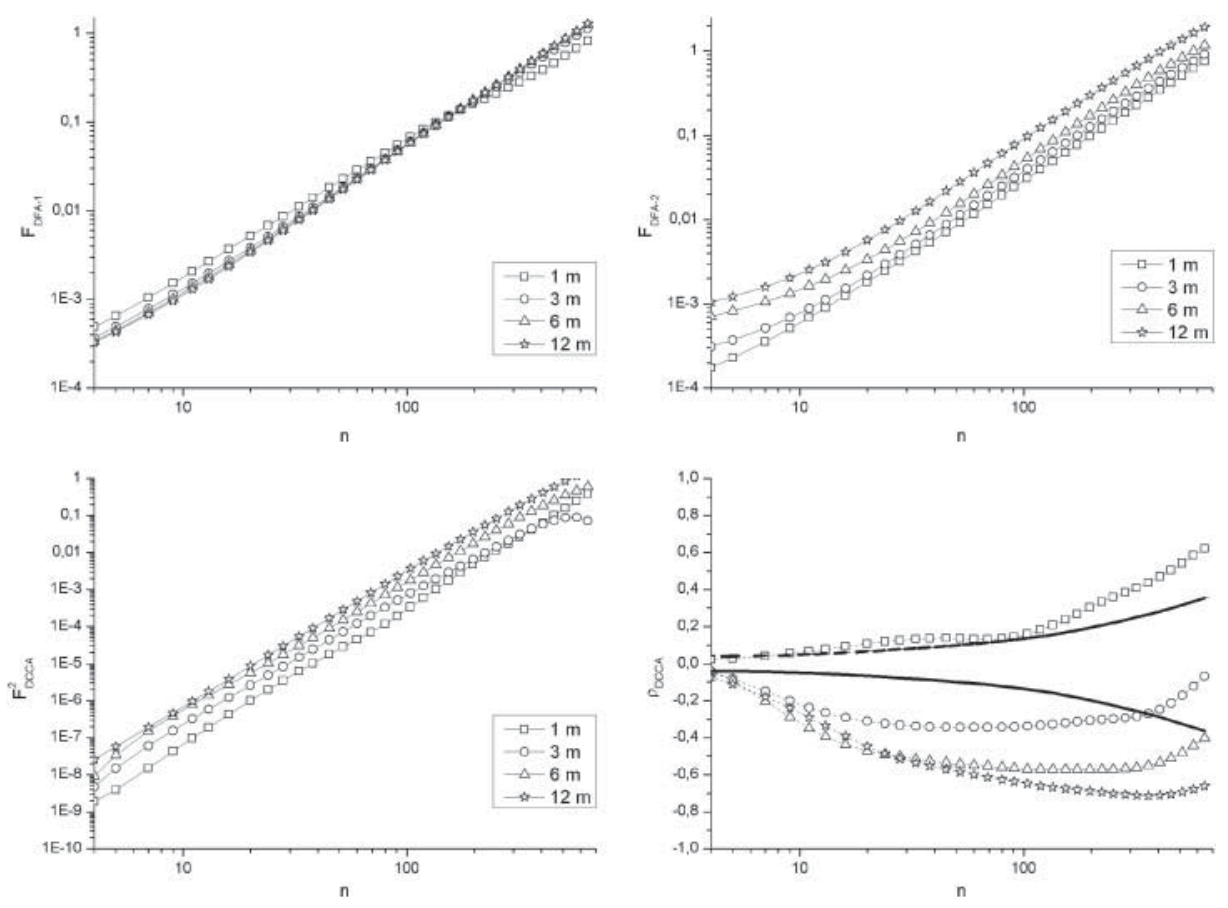

Figure 5. DCCA correlation coefficient for Lithuania. 

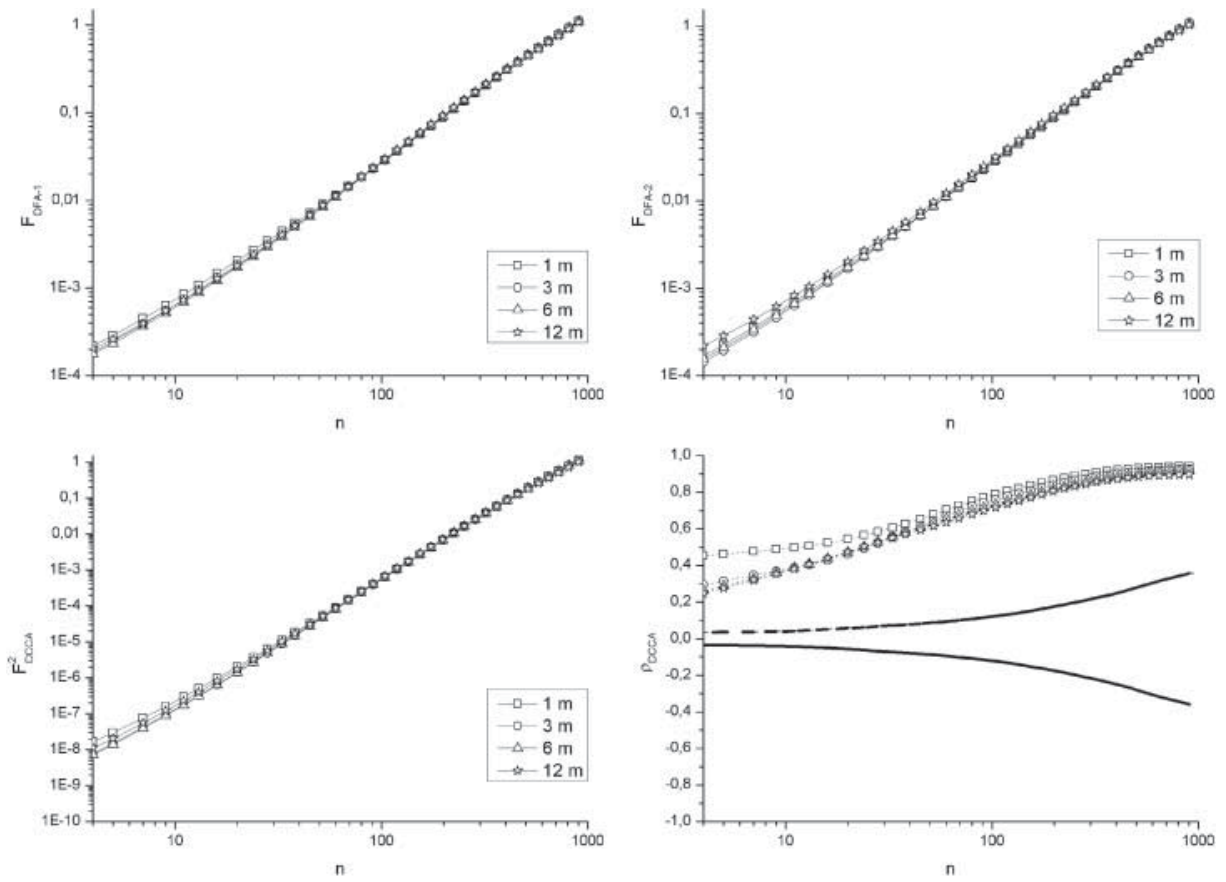

Figure 6. DCCA correlation coefficient for Denmark.

being used in the context of non-stationary time series (Peng et al., 1994). ${ }^{6}$ Originally used to explain behavior in natural science phenomena, both techniques could also be applied to economic time series, namely financial data (see, for example, Podobnik, Horvatic, Petersen, \& Stanley, 2009, or Wang, Wei, \& Wu, 2013, among others).

As DCCA has the advantage of studying financial series even when they are not stationary, we can analyze their behavior directly from equation (4), rather than calculating CIP differentials. As previously mentioned, the use of CIP differentials is an alternative way to study this question, analyzing whether they are stationary. Physical statistics could even be used to analyze CIP differentials in future work.

Considering the data given by $x_{k}$ and $y_{k}$ with $k=1, \ldots, t$ equidistant observations. The first step of DCCA is obtained by integrating both series and calculating the values: $x(t)=\sum_{k=1}^{t} x_{k}$ and $y(t)=\sum_{k=1}^{t} y_{k}$. Afterwards, we divide them into $N-n$ overlapping boxes, defining for each box the local trend $\left(\tilde{x}_{k}\right.$ and $\left.\tilde{y}_{k}\right)$, using ordinary least squares. After this, the detrended series is calculated; i.e. the difference between the original

\footnotetext{
${ }^{6}$ In our study, we use a correlation coefficient from DCCA which also implies calculation of detrended fluctuation analysis (DFA), which analyzes the behavior of individual series. However, we use the exponent from DFA only indirectly. So we do not explain this methodology in detail. For more information, see the original work on DFA (Peng et al., 1994). For a brief literature review, see the work by Ferreira and Dionísio (2014).
} 
values and its trend. Then, we calculate the covariance of the residuals in each box given by $f_{D C C A}^{2}=\frac{1}{n-1} \sum_{k=i}^{i+n}\left(x_{k}-\tilde{x}_{k}\right)\left(y_{k}-\tilde{y}_{k}\right)$. Finally, the detrended covariance is calculated summing all $N-n$ boxes of size $n$, given by $F_{D C C A}^{2}(n)=\frac{1}{(N-n)} \sum_{i=1}^{N-n} f_{D C C A}^{2}$. This process should be repeated for different length boxes in order to find the relationship between DCCA fluctuation function and $n$ size, which allows us to find the long-range crosscorrelation $F_{D C C A}(n)$ given by the power law $F_{D C C A}(n) \tilde{n}^{\lambda}$. Interpretation of $\lambda$ is quite similar to interpretation of DFA: if $\lambda$ is equal to 0.5 , series have no long range cross-correlation; a $\lambda$ greater than 0.5 means persistent longrange cross-correlations while values lower than 0.5 mean anti-persistent cross-correlation (a large value in one variable is likely to be followed by a small value in another, and vice versa).

DCCA gives us information about cross-correlation between series but does not quantify that value. In order to make that quantification, from the results of DCCA between $x$ and $y$ and DFA for each series, Zebende (2011) created the correlation coefficient given by $\rho_{D C C A}=\frac{F_{D C C A}^{2}}{F_{D F A}\{i\}} F_{D F A\{y i\}}$. This coefficient has the general properties of one correlation coefficient, namely $-1 \leq \rho_{D C C A} \leq 1$. A value of $\rho_{D C C A}=0$ means that there is no cross-correlation between series, while a positive or negative value means, respectively, cross-correlation or anti cross-correlation between series.
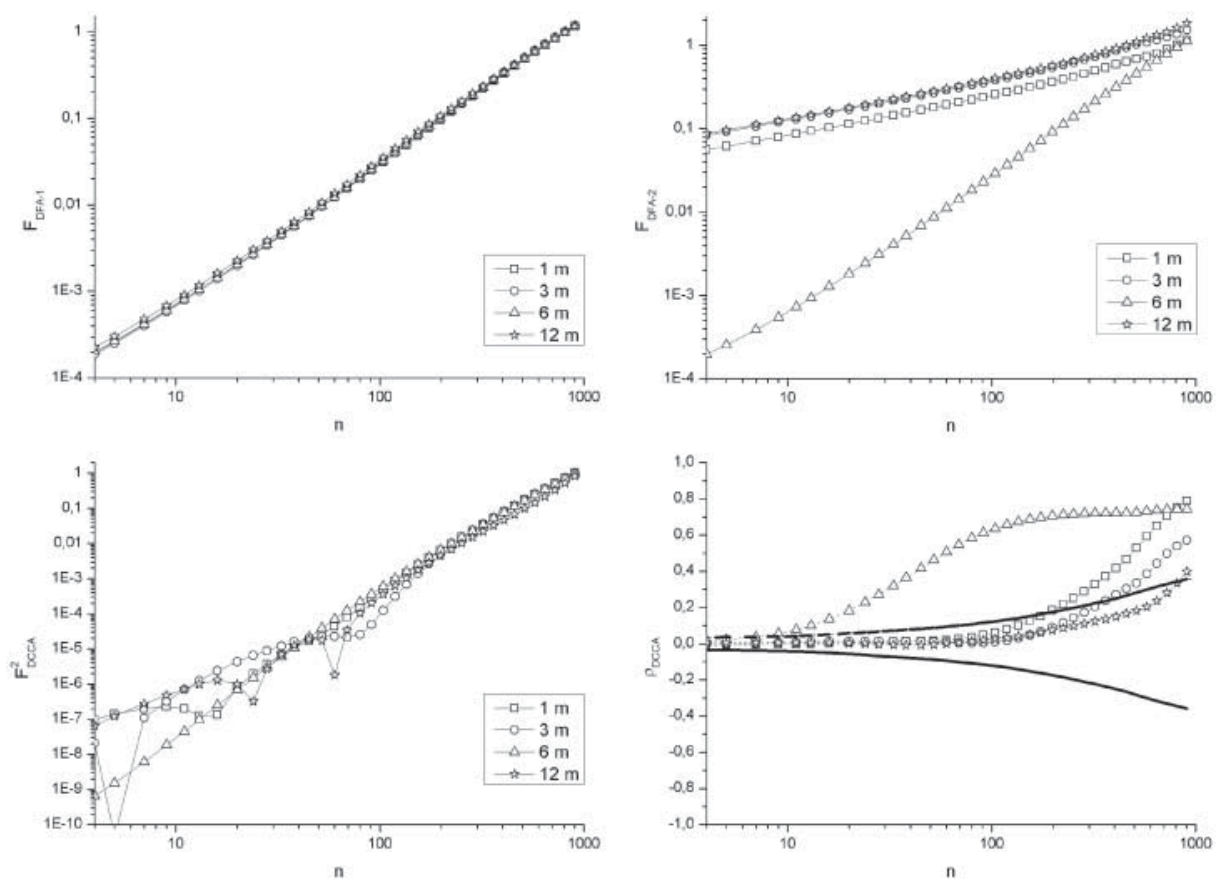

Figure 7. DCCA correlation coefficient for Sweden. 

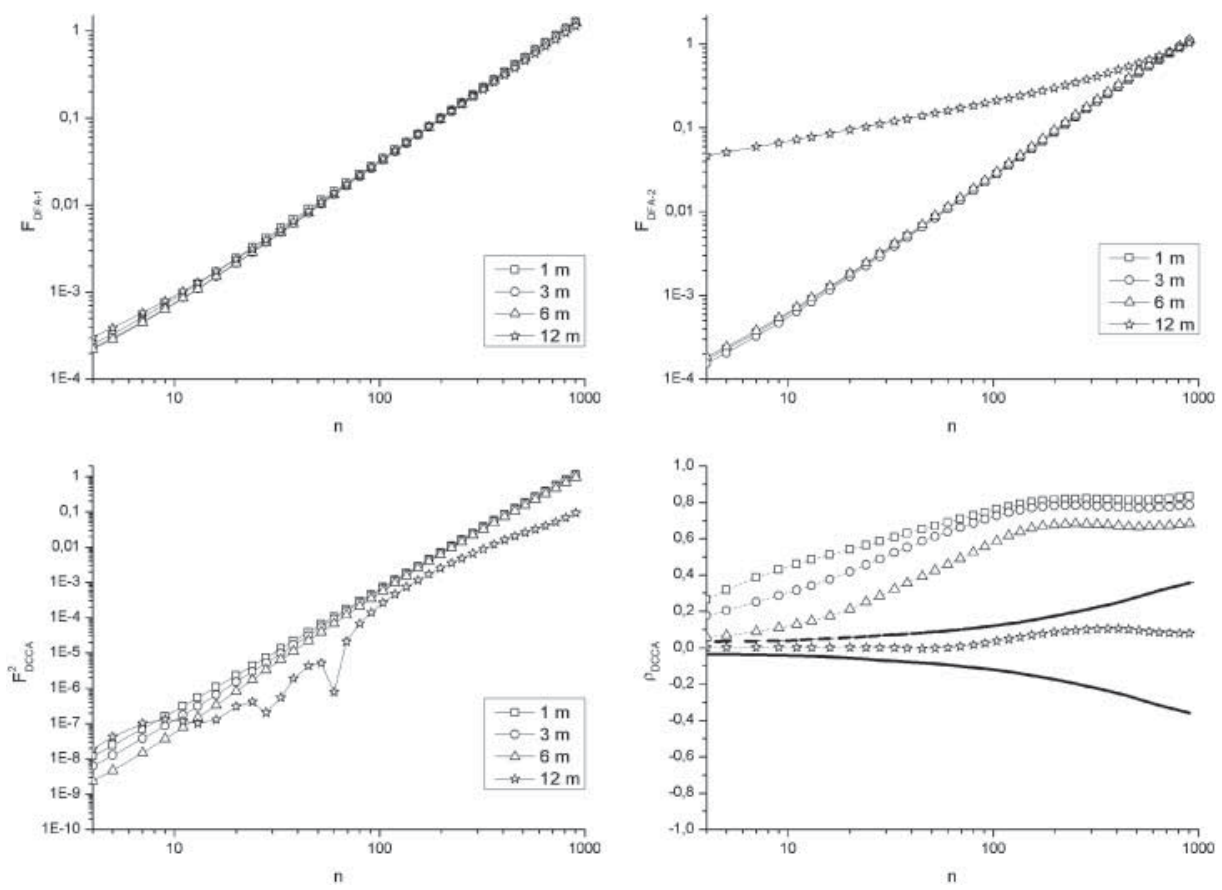

Figure 8. DCCA correlation coefficient for UK.

According to Podobnik, Jiang, Zhou, \& Stanley (2011), we can test the significance of this correlation coefficient. The authors estimate the critical points for this test and we use them to test our coefficients.

\section{Results of Application of DCCA to CIP}

Our objective is to apply DCCA to both variables present in equation (4). As referred to previously, DCCA has the advantage of being applied in the presence of non-stationary time series, such as those applied in CIP. In the context of CIP, we interpret the existence of significant positive cross-correlation as evidence of CIP in its weak form, meaning there is evidence of financial integration. When correlation is not positively significant, it means there is some violation of CIP. With the identified methodology, we calculated the long-range correlation coefficient for our data. The methodology we propose calculates, for each country and maturity, one correlation coefficient for each length box we use in the DFA and DCCA analysis. Table 2 presents the average correlation coefficient for each country and maturity. ${ }^{7}$

We can conclude that almost half the correlation coefficients are negative, meaning that the relation between variables in equation (4) is contrary to

${ }^{7}$ Since presentation of all results is not practical due to space constraints, we do not show them. However, results are available on request. 

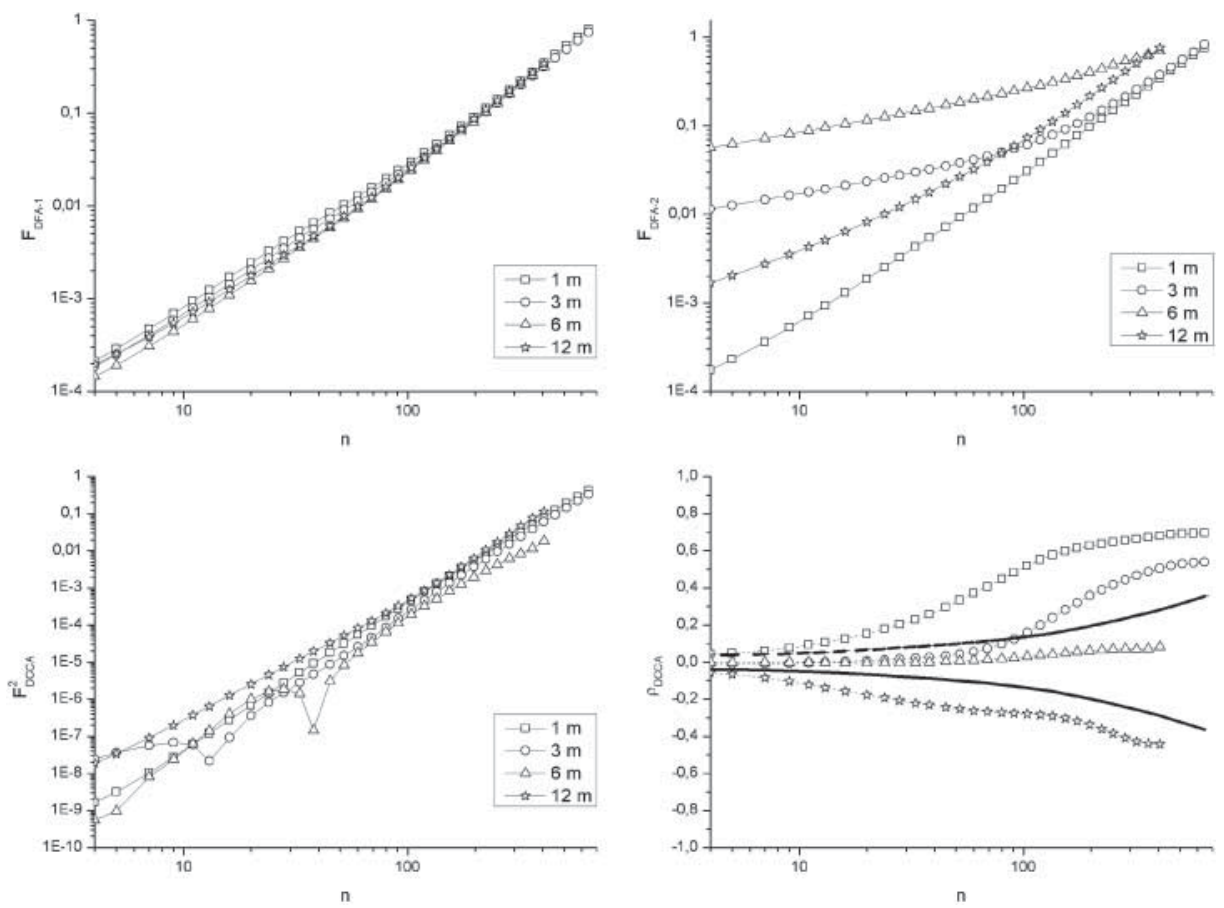

Figure 9. DCCA correlation coefficient for Bulgaria.

that expected by CIP. As well as this conclusion, Denmark is the country with the highest correlation coefficients, in different maturities, followed by the UK.

The average correlation coefficient could give us some information about which countries have less correlation between the variables considered in equation (4). However, it does not give us any information about the significance of that correlation. So we proceeded to test the respective hypothesis. The null hypothesis is that both variables are uncorrelated, meaning that $\rho_{D C C A}=0$. The alternative hypothesis rejects this and implies the existence of significant correlation between variables, which could be interpreted as verification of CIP at least in its weak form.

With our data, and according to each country's number of observations, we simulated the critical values at $90 \%, 95 \%$ and $99 \%$ for testing, according to the procedure of Podobnik et al. (2011). Figure 1 shows the behavior of critical values for series with 523 and 2400 observations, from the minimum length box $(n=4)$ to the maximum $(n=N / 4)$. We have the same figures for the number of observations used in this paper, which are supplied on request.

We compiled all the information on correlation coefficients for each country, maturity and length boxes, with critical values at $95 \%$ level, as seen in Figures 2 to 13 . At the top we can see the DFA exponents for each series used in the test ( $i_{t}$ on the left and $i c_{t}^{*}$ on the right) and at the bottom the 
absolute values of $F_{D C C A}^{2}$ (left) and $\rho_{D C C A}$ (right). In the last one, the full line identifies the $95 \%$ confidence level, while the other lines represent the correlation coefficient for each maturity, depending on the length boxes. While the correlation coefficient is above the upper line, the correlation coefficient is positively significant, showing evidence of CIP in its weak form.

We start the empirical analysis with the countries that have already adopted the euro: Estonia, Latvia and Slovakia (respectively, Figures 2, 3 and 4). For these countries, evidence is against verification of CIP. In fact, Estonia has only minor evidence of CIP verification for shorter boxes for 1-month maturity. In Slovakia the evidence of CIP is also minimal and for 1-month maturity. Latvia has no evidence of CIP.

Besides Estonia, Latvia and Slovakia, which have already adopted the euro, Lithuania joined the currency at the beginning of 2015. For this country, confirmation of CIP is also very important, as previously stated. However, and as for the previous countries analyzed, CIP is only confirmed for 1-month maturity. For other maturities, CIP is rejected (see Figure 5).

The remaining countries in our sample could be divided into two groups: countries that were EU members when the euro was created (Denmark, Sweden and the UK) and countries that entered the EU after its creation (Bulgaria, the Czech Republic, Hungary, Poland and Romania).

The first group is composed of three countries that decided not to adopt the euro, and their results can be consulted in Figures 6,7 and 8. Denmark
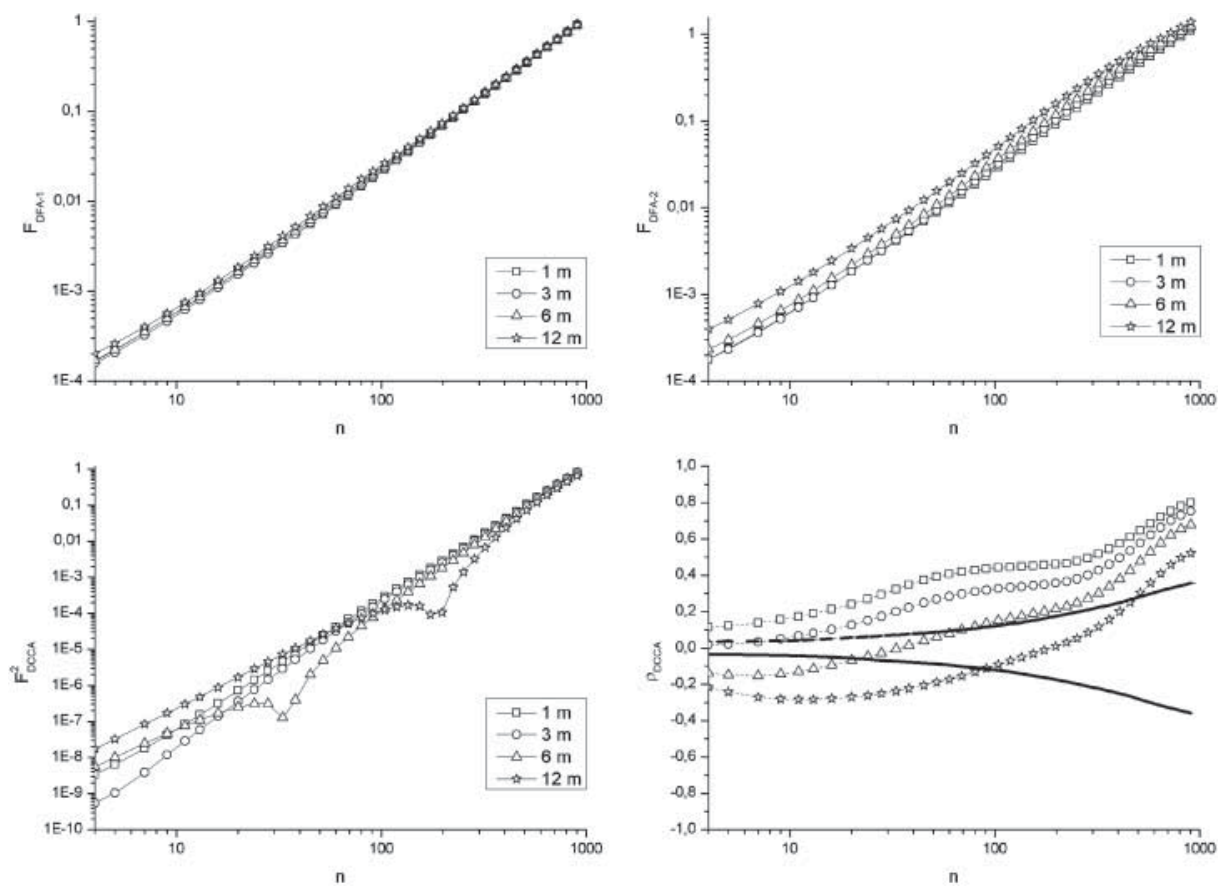

Figure 10. DCCA correlation coefficient for the Czech Republic. 


\section{Paulo Ferreira \& Andreia Dionísio}

has strong evidence of CIP, with the correlation coefficient always being positively significant, independently of the maturity or box dimension. The evidence is also relatively strong for the UK, while for Sweden the coefficient is significant for 6-month maturity and for other maturities it is significant for higher boxes.

The last group includes those countries that entered the EU after creation of the euro but kept their own currency: Bulgaria, the Czech Republic, Hungary, Poland and Romania (Figures 9 to 13).

Bulgaria and the Czech Republic show some evidence of CIP verification (greater in the latter country). The remaining countries (Hungary, Poland and Romania) do not show any evidence of CIP verification.

Our results are in line with previous studies made of the same countries. For example, for the first group of countries we study (Eurozone members), few studies include these countries, due to the scarcity of data. Regarding Slovakia, Herrmann and Jochem (2003) find evidence of CIP rejection, which is confirmed in our results. For the other two countries (Estonia and Latvia), to the authors' knowledge, there are no studies on CIP. The same occurs with Lithuania, which joined the Eurozone at the beginning of 2015,

Another group is formed by countries that decided not to adopt the common currency when it was created (Denmark, Sweden and the UK). For these countries, the results are coherent with previous studies. In fact, in the set of countries used in this paper, these countries have more studies on CIP, due
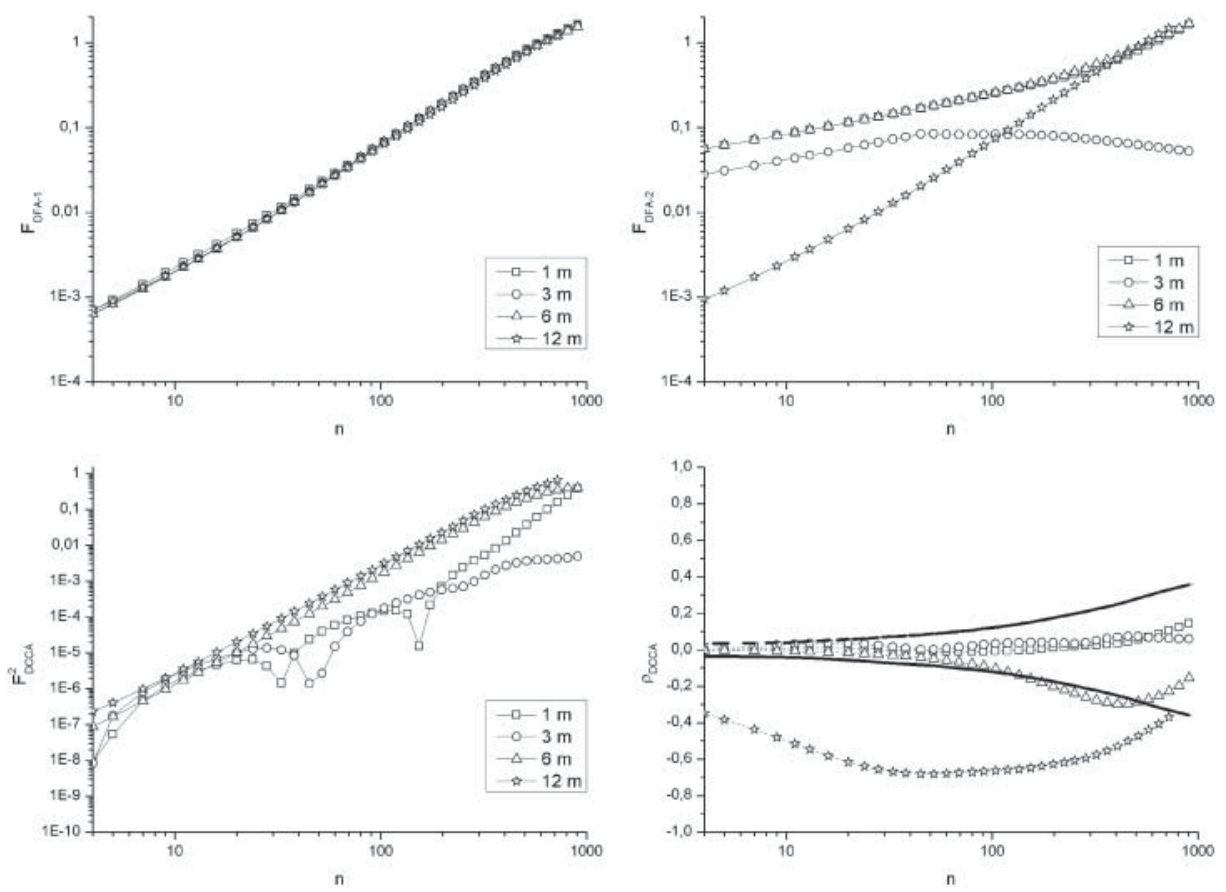

Figure 11. DCCA correlation coefficient for Hungary. 
to the fact that they belonged to the EU before the creation of the common currency. Similar results can be found in studies by Ferreira et al. (2010), Holmes and Pentecost $(1996,1999)$ or Lemmen (1996).

Concerning the other countries we study in this paper, as far as we can know, Bulgaria has no studies on CIP, so results cannot be compared. Regarding the Czech Republic, although studies are not numerous, they show similar patterns in this economy to those of other countries that adopted the common currency, with some support for CIP verification (see, for example, Ferreira, 2011, or Filipozzi and Staehr, 2013). The results for Hungary, Poland and Romania, which do not show any evidence of CIP verification, are in line with previous studies of these countries: for Hungary and Poland see, for example, Ferreira (2011), Herrmann and Jochem (2003) or Filipozzi and Staehr (2013). In the Romanian case, the study by Filipozzi and Staehr (2013) is the only one including this country.

One possible problem with our data is the fact that we have different sample dimensions for our countries, due to different data availability. It is useful to study time series from the moment they become available, to achieve more conclusive results. However, we applied our methodology to these countries from March 2004 and the results are qualitatively similar, giving us information about the robustness of our results. The exception is found in the results for the Czech Republic: for this country, results with that smaller sample, clearly point to evidence of CIP verification. However, this
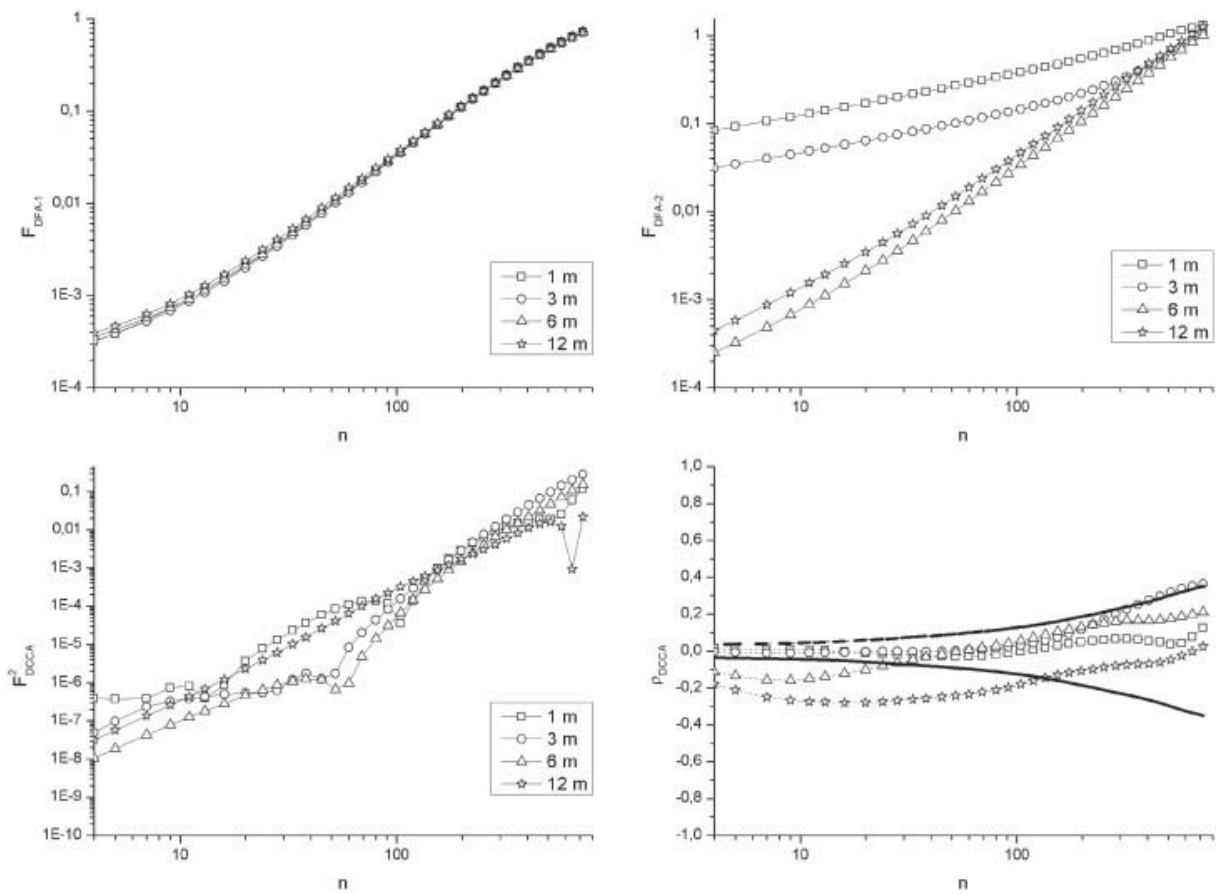

Figure 12. DCCA correlation coefficient for Poland. 

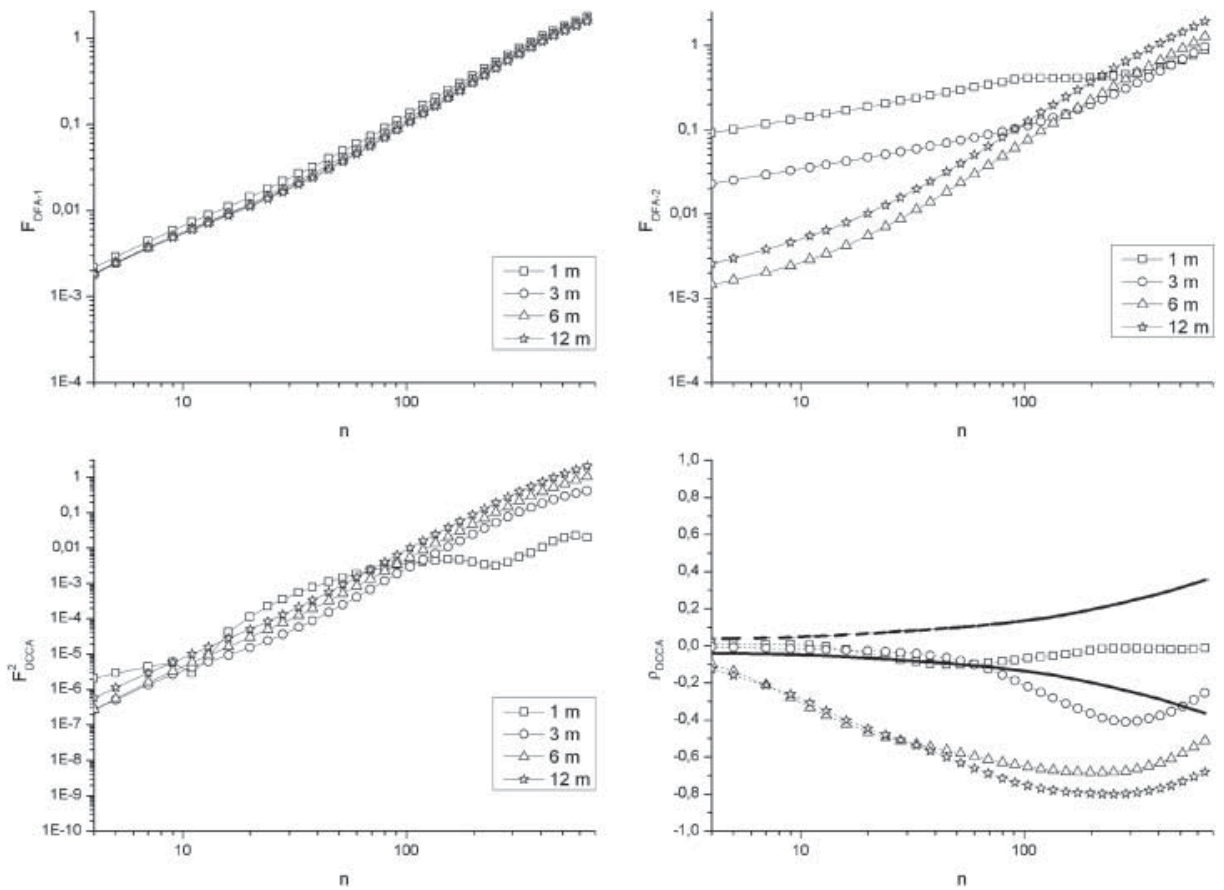

Figure 13. DCCA correlation coefficient for Romania.

is an expected result and also coherent with previous studies, which were stated above.

\section{Conclusions}

With the advance of the integration process between EU countries, with some of them adopting a common currency, levels of financial integration are expected to rise. Besides the adoption of the same currency by some countries, the fact that capital controls were progressively abolished in the EU should lead to this result. However, this study, as others, shows this may not be the case.

One explanation may be that some remaining factors could prevent complete financial integration. The political risk, defined by Aliber (1973), and related to the possibility of reinserting controls, is one of them. The recent crisis in the euro, which even raised the hypothesis of some countries exiting the common currency, could be interpreted as a particular case of this problem. The existence of asymmetric information, transaction costs or different fiscal treatment of returns in the different countries are other factors that can explain our conclusions. These are not legal barriers but they can affect capital mobility, implying that countries do not fully exploit the potential benefits of financial integration (see, for example, Ferreira, 2011). 
With the absence of transaction costs, when assets are really similar, CIP differentials are expected to be nil. If they exist, they are expected to decrease until all profitable opportunities are eliminated and evidence in favor of CIP is found. However, it is also possible that agents do not consider all countries' assets as similar. In this case, CIP could also fail. This could be one of the causes of CIP deviations in some of the countries. Probably, investors do not feel that all European assets have the same risks.

The fact that, during the sample period, the Eurozone has experienced a severe financial crisis, in part due to problems in the money market, could also explain some of those CIP deviations. Indeed, Taylor (1989) presents market turbulence as a possible cause of those deviations. Furthermore, studies such as those by Baba and Packer (2009a, 2009b) and Hui, Genberg, and Chung (2011) also point to deviations linked with market turbulence. These authors advance three main conclusions about CIP deviations: (i) differences in the counterparty risk between European and US financial institutions; (ii) there was some behavior by both monetary institutions to stabilize swap markets (after identifying problems of liquidity in these markets); (iii) less liquidity in markets, during the crisis. Although the first of the three motives should not be directly considered, the behavior of different monetary authorities in these European countries could justify some deviations. However, liquidity problems could be a reason for CIP failure. In fact, mainly in countries that joined the EU in 2004 or later, CIP rejection could also be a signal of some underdevelopment or lack of liquidity of their financial markets, especially when compared with other EU members (see, for example, Ferreira, 2011 or Herrmann and Jochem, 2003).

It is also important to understand that CIP violation could be caused by some frictions that provoke differentials but do not mean riskless profit opportunities.

First, in the presence of transaction costs, CIP differentials do not necessarily mean the existence of profit opportunities. If the differentials are smaller than the transaction costs, they do not generate profit opportunities. Based on this assumption, Frenkel and Levich $(1975,1977)$ elaborate a neutral band for parity, within which differentials are not synonymous with riskless profit opportunities. Outside this band, differentials could mean different tax treatment, sovereign risk, government controls, non-infinite demand and supply elasticities, transaction costs, information costs, capital controls, imperfect asset substitutability or even measurement errors. The absence of long-range correlation between markets could be interpreted as differentials outside the neutral band. Alternatively, rejection of CIP could also be a sign of monetary autonomy. However, in the case of countries that are in the Eurozone (or which will enter), this should not be a reason for CIP deviations, since those countries are subject to strict rules regarding their adoption of the common currency, as far as monetary policies are concerned. For countries that are non-euro members, this could be a motive for deviations.

But the most important conclusion for euro members, in our view, is that our results could show that some countries did not gain the advantages expected from full financial integration. Furthermore, rejection of CIP 
could imply that those countries did not have the capacity to face asymmetric shocks, which is a great challenge for their governments. The same conclusion should be made for Lithuania, which entered the Eurozone recently and also shows evidence against CIP. For these countries, since they have no monetary policy instruments of their own, and because budgetary measures are also limited, they could face difficulties in solving possible economic problems.

For the remaining countries, the absence of CIP verification could be a problem if they are interested in adopting the common currency. It is interesting that CIP evidence is more visible in countries that have been longer in the EU (Denmark, Sweden and the UK), showing evidence in favor of financial integration. The pattern of correlation for integrated economies should be something like the Danish results, where CIP is always confirmed. This could be explained, for example, by Denmark's possible interest in joining the Eurozone, as has been noted in the past.

\section{Acknowledgements}

The authors are pleased to acknowledge financial support from Fundação para a Ciência e a Tecnologia and FEDER/COMPETE (grant UID/ECO/04007/2013).

\section{References}

Aliber, R. (1973). The interest rate parity theorem: A reinterpretation. Journal of Political Economy, 81, 1451-1459.

Baba, N., \& Packer, F. (2009a). Interpreting deviations from covered interest parity during the financial market turmoil of 2007-08. Journal of Banking \& Finance, 33, 1953-1962.

Baba, N., \& Packer, F. (2009b). From turmoil to crisis: Dislocations in the FX swap market before and after the failure of Lehman Brothers. BIS Working Papers No 285.

Ferreira, P. (2011). Monetary Integration in the European Union. Journal of Emerging Market Finance, 10, 93-120.

Ferreira, P., Dionísio, A., \& Zebende, Z. (2014). Why does the Euro fail? The DCCA approach. CEFAGE-UE Working Paper 2014/15

Ferreira, P., \& Dionísio, A. (2014). Revisiting serial dependence in the stock markets of the G7 countries, Portugal, Spain and Greece. Applied Financial Economics, 24, 319-331.

Ferreira, P., Dionísio, A., \& Pires, C. (2010). Adopt the Euro? The GME approach. Journal of Economic Interaction and Coordination, 5, 231-247.

Filipozzi, F., \& Staehr, K. (2013). Covered interest parity and the global financial crisis in four central and Eastern European Countries. Eastern European Economics, 51(1), 21-35.

Frankel, J. (1992). Measuring international capital mobility: A review. The American Economic Review, $82,197-202$.

Frankel, J. (1993). International Monetary Integration: Relations between Interest Rates and Exchange Rates, edited by D. Das. International Finance - contemporary issues. London: Routledge.

Frenkel, J., \& Levich, R. (1975). Covered interest arbitrage: Unexploited profits? Journal of Political Economy, 83, 325-338.

Frenkel, J., \& Levich, R. (1977). Transaction costs and interest arbitrage: Tranquil versus turbulent periods. Journal of Political Economy, 85, 1209-1226.

Herrmann, S., \& Jochem, A. (2003). The international integration of money markets in the Central and East European accession countries: Deviations from covered interest parity, capital controls and inefficiencies in the financial sector. Discussion paper 07/03, Economic Research Centre of the Deutsche Bundesbank, Frankfurt am Main. 
Holmes, M. (2003). Monetary integration and the European Union: An assessment of the impact of capital controls, exchange rate turbulence and the introduction of the euro. European Review of Economics and Finance, 2, 3-18.

Holmes, M., \& Pentecost, E. (1996). Changes in the degree of monetary integration within the European Community in the 1980 s: Some econometric tests. Journal of Economic Studies, 23, 4-17.

Holmes, M., \& Pentecost, E. (1999). A new test of international financial integration with application to the European Union. Journal of Economic Integration, 14(1), 1-12.

Holmes, M., \& Wu, Y. (1997). Capital controls and covered interest parity in the EU: Evidence from a panel-data unit root test. Weltwirtschaflitches Archiv, 133, 76-89.

Hui, C., Genberg, H., \& Chung, T. (2011). Funding liquidity risk and deviations from interest rate parity during the financial crisis of 2007-2009. International Journal of Financial Economics, 16, 307-323.

Lemmen, J. (1996). Monetary integration in the European Union - Measurement and Determination. Tilburg University: Center for Economic Research.

Peng, C., Buldyrev, S., Havlin, S., Simons, M., Stanley, H., \& Goldberger, A. (1994). Mosaic organization of DNA nucleotides. Physical Review E, 49, 1685-1689.

Podobnik, B., \& Stanley, H. (2008). Detrended cross-correlation analysis: A new method for analyzing two nonstationary time series. Physical Review Letters, 100, 084102.

Podobnik, B., Horvatic. D., Petersen, A., \& Stanley, H. (2009). Cross-correlations between volume change and price change. PNAS, 106(52), 22079-22084.

Podobnik, B., Jiang, Z., Zhou, W., \& Stanley, H. (2011). Statistical tests for power-law cross-correlated processes. Physical Review E, 84, 066118.

Taylor, M. (1989). Covered interest arbitrage and market turbulence. Economic Journal, 99, 376-391.

Wang, Y., Wei, Y., \& Wu, C. (2013). Cross-correlations between Chinese A-share and B-share markets. Physica A, 389, 5468-5478.

Zebende, G. (2011). DCCA cross-correlation coefficient: Quantifying level of cross-correlation. Physica A, 390, 614-618. 